\title{
CARACTERIZAÇÃO DOS CURSOS DE HANDEBOL NAS INSTITUIÇÕES DE ENSINO SUPERIOR PÚBLICAS
}

\author{
Heloisa Helena Baldy dos Reis, Universidade Estadual de Campinas, Campinas, São \\ Paulo - Brasil \\ Rafael Moreno Castellani, Universidade Estadual de Campinas, Campinas, São Paulo - \\ Brasil
}

\begin{abstract}
RESUMO
Este artigo apresenta uma pesquisa sobre o perfil dos professores e cursos de handebol das Instituições de Ensino Superior Públicas brasileiras. A pesquisa foi realizada a partir do depoimento dos seus professores participantes do II Encontro Nacional de Professores de Handebol, organizado pela Confederação Brasileira de Handebol. De um total de 85 professores de Instituições de Ensino Superior (IES) de todo o território nacional, inscritos no evento, participaram da pesquisa 43 professores, sendo 13 de IES públicas (de um total de 20), 29 de IES privadas (de um total de 65) e um(a) de ambas. Foi aplicado um questionário contendo 10 perguntas, em sua maioria fechada e em alguns casos se permitia ainda a complementação da resposta. Vimos que a esperada titulação mínima de mestre para os docentes de IES públicas, não foi confirmada já que dentre os 14 participantes $57 \%$ deles são especialistas ou graduados. Por sua vez, o fato de $86 \%$ destes professores já terem sido handebolistas denota a forte relação que possuem com a modalidade.
\end{abstract}

Palavras-Chave: Handebol; Formação profissional; Graduação em Educação Física

\section{THE PROFILE OF COURSES OF HANDBALL IN PUBLIC INSTITUTIONS OF HIGHER EDUCATION}

\begin{abstract}
This article presents research on the backgrounds of teachers and courses handball of Public Higher Education Institutions in Brazil. The survey was conducted from the testimony of his teachers participating in the II National Meeting of Teachers of Handball, organized by the Brazilian Handball Confederation. From a total of 85 teachers of Higher Education Institutions (IES) from throughout the country, event registrants, 43 teachers participated in the survey, and 13 of IES public (a total of 20), 29 private HEIs (a total of 65 ) and one (of both). We used a questionnaire containing 10 questions, mostly closed and in some cases are still allowed to supplement the response. We have seen that the expected

Conexões: revista da Faculdade de Educação Física da UNICAMP, Campinas, v. 10, n. 2, p. 103-120, maio/ago. 2012. 103 ISSN: 1983-9030
\end{abstract}


titration minimum for master teachers of public IES was not confirmed since among the 14 participants $57 \%$ of them are graduates or specialists. In turn, the fact that $86 \%$ of these teachers have already been handball players, what denotes the strong relationship they have with the sport.

Key-Words: Handball, Vocational training; Degree in Physical Education; 


\section{INTRODUÇÃO}

As instituições de ensino superior brasileiras em sua grande maioria são universidades ${ }^{1}$. Espera-se destas uma formação de excelência nos cursos de graduação já que o pilar das universidades se alicerça no ensino, na pesquisa e na extensão.

Diante de tal fato e expectativa de conhecermos a realidade, nos propusemos a pesquisar o perfil dos professores e dos cursos de handebol das IES públicas a partir do depoimento dos seus professores participantes do II Encontro Nacional de Professores de Handebol, organizado pela $\mathrm{CBHb}^{2}$.

Uma das poucas pesquisas acadêmicas sobre o ensino de handebol ${ }^{3}$ em curso superior foi realizada por Souza em 2007. Para esta

Deve-se levar sempre em consideração os fins a que se destinam os cursos, ou seja: na licenciatura, o desenvolvimento de conhecimentos, experiências e cultura sobre as possibilidades de utilização do esporte como meio para se desenvolver e atingir a adoção de um estilo de vida ativo e para oportunizar ao indivíduo a busca por superar-se segundo a própria intencionalidade, e no Bacharelado, para que se possa fazer uso dos conteúdos e práticas do esporte como cultura, capacitação e potencialização do indivíduo para a busca de superações e performance. $^{1: 231}$

Nossa pesquisa foi realizada com professores de IES públicas sem distinguir o que esses entendiam pelo ensino do handebol nos cursos de bacharelado ou licenciatura em Educação Física. A distinção entre ambos só ocorreu quando o professor tinha que identificar de qual curso o mesmo era professor/a.

As disciplinas de esportes nos cursos de formação superior são comumente vistas como cursos práticos ${ }^{4}$, pautadas sob uma visão limitada e simplista do campo devendo ser revista

\footnotetext{
${ }^{1}$ De um total de "959 cursos superiores de Educação Física, 550 deles são de Universidades, 248 nas de natureza pública e 302 particular. Os demais estão distribuídos nos Centros Universitários (128), Faculdades Integradas (60), Faculdades Isoladas (194) e Institutos de Educação Superior (27)". (CASTELLANI FILHO, 2012, p. 9 - grifos do autor). ${ }^{2}$

${ }^{2}$ De um total de 85 professores de IES de todo o Brasil inscritos no evento, participaram da pesquisa 43 professores, sendo 13 de IES públicas (de um total de 20), 29 de IES privadas (de um total de 65) e um(a) de ambas (de um total de $85)$.

${ }^{3}$ Em nova consulta ao banco de teses e periódicos da Capes (acesso em 03 jul. 2012), encontramos, dentre as 92 existentes a partir da palavra-chave Handebol, somente uma tese (TERRA, 1996) ${ }^{3}$ e nenhum artigo com a proposta de análise do handebol nos cursos de licenciatura das IES brasileiras.

${ }^{4}$ Sobre os limites da formação de professores em Educação Física consultar: RODRIGUES, Anegleyce Teodoro. ${ }^{4}$ A questão da formação de professores de educação física e a concepção de professor enquanto intelectual - reflexivo transformador. Pensar a Prática, Goiânia, v. 1, p. 38-47, 1998.

Conexões: revista da Faculdade de Educação Física da UNICAMP, Campinas, v. 10, n. 2, p. 103-120, maio/ago. 2012.105 ISSN: 1983-9030
} 
e bem analisada para que não continue se refletindo na formação de professores de Educação Física a deformação no desconhecimento da abrangência e complexidade do subcampo denominado handebol. Para Tardif (2002 apud SOUZA, 2007) 1:54 a "oposição tradicional em "teoria e prática" é muito pouco pertinente e demasiadamente simplificadora no que se refere aos aspectos epistemológico e conceitual".

Souza $^{1}$ realizou pesquisa com 17 professores de disciplinas esportivas de cinco IES de Goiás, entre IES públicas e privadas e observou que:

[...] nos conteúdos definidos pelos professores em seus planos de ensino os mesmos
entrevêem o ensino das disciplinas esportivas coletivas de forma simplista e reducionista,
pois privilegiam somente conteúdos técnicos, táticos e conhecimento sobre regras e
organização de competição. A nossa pesquisa teve como objetivo traçar o perfil dos professores de handebol das IES públicas e os métodos e conteúdos utilizados na disciplina de handebol.

Para isto, utilizamos como instrumento de coleta um questionário composto por questões abertas e fechadas sobre o que e como os professores ensinam os conteúdos específicos do handebol. Perguntou-se também a eles qual o método ou métodos de ensino-aprendizagem que eles utilizavam para ensinar handebol, tendo como alternativas: método parcial, método global, método misto, Iniciação Esportiva Universal, ou outro. Neste último com espaço para a denominação de outro método de ensino-aprendizagem. Em outra questão, buscou-se saber deles quais os conteúdos que ensinavam em suas aulas de handebol. As alternativas eram: fundamentos do handebol, postos específicos de pontas e pivô, postos específicos de armadores, posto específico de goleiro, regras, histórico, meios táticos defensivos, meios táticos ofensivos, sistemas defensivos, sistemas ofensivos, periodização do treinamento em handebol, mini-handebol, handebol de praia. Nas alternativas sobre os meios táticos e os sistemas, foram solicitadas as especificações de quais seriam esses, visto que também objetivamos analisar se os professores das IES públicas tem conhecimento da produção acadêmica veiculada na literatura sobre sua disciplina. Neste aspecto, Souza ${ }^{1}$ encontrou em sua pesquisa que há, entre os 17 professores estudados, falta de conhecimento específico sobre metodologias e procedimentos pedagógicos.

\section{METODOLOGIA}

Ao todo participaram da pesquisa 14 professores representantes de Instituições de Ensino

Conexões: revista da Faculdade de Educação Física da UNICAMP, Campinas, v. 10, n. 2, p. 103-120, maio/ago. 2012.106 ISSN: 1983-9030 
Superior Brasileira Públicas na condição de docente da disciplina de Handebol que participaram do II Encontro Nacional de Professores de Handebol, organizado pela CBHb na cidade de Foz do Iguaçu/PR.

Foi aplicado um questionário contendo 10 perguntas nas quais, em alguns casos, se necessário, permitiam a complementação das informações. Estes foram distribuídos no segundo dia do Encontro e recolhidos até o final do evento (quarto dia). Do total aproximado de 80 questionários entregues a todos os participantes, 43 retornaram a nós (contando neste cômputo com professores de IES particulares) preenchidos, dentre os quais somente 14 representavam IES públicas. Tal instrumento buscou levantar elementos que permitissem a caracterização dos traços gerais do perfil dos professores(as) e cursos de handebol das instituições públicas de ensino superior brasileiras.

\section{RESULTADOS E DISCUSSÃO}

A apresentação dos resultados de nossa pesquisa, assim como a discussão dos mesmos, será realizada em três etapas distintas. Na primeira delas, iremos explicitar a característica do corpo docente dos cursos analisados, retratando sua formação, sua experiência com a modalidade handebol e a modalidade de curso que lecionam. Por sua vez, a segunda etapa será responsável por nos esclarecer as características das IES e as condições oferecidas por elas aos docentes para o desenvolvimento dos cursos de handebol. Por fim, na terceira, e última, etapa de análise iremos retratar o perfil dos cursos de handebol que são oferecidos por estes professores nas suas respectivas IES, explicitando os conteúdos referentes ao handebol ensinados e os métodos de ensino adotados pelos professores durante o curso.

Por tratarmos neste artigo com informações referentes aos professores que lecionam somente em IES públicas, esperávamos que a grande parcela dos participantes possuísse uma titulação mínima de mestre, já que nas duas últimas décadas houve um grande esforço para a titulação do corpo docente das IES públicas. É comum o oferecimento de condições para a realização de cursos de mestrado e doutorado e mais recentemente, em vários estados do país, as IES públicas só contratam professores com titulação mínima de doutor.

No entanto, ao contrário de nossa hipótese, verificamos a partir do Gráfico 1 que a parcela 
de doutores representa somente $7 \%$ do total, ou melhor, apenas 1 professor dentre os participantes da pesquisa possui a titulação mínima de Doutor. ${ }^{5}$ A metade dos professores participantes $(50 \%)$ possui a titulação de Especialista, cinco professores (representando $36 \%$ ) possuem a titulação de Mestre e ainda há um professor que possui apenas a graduação.

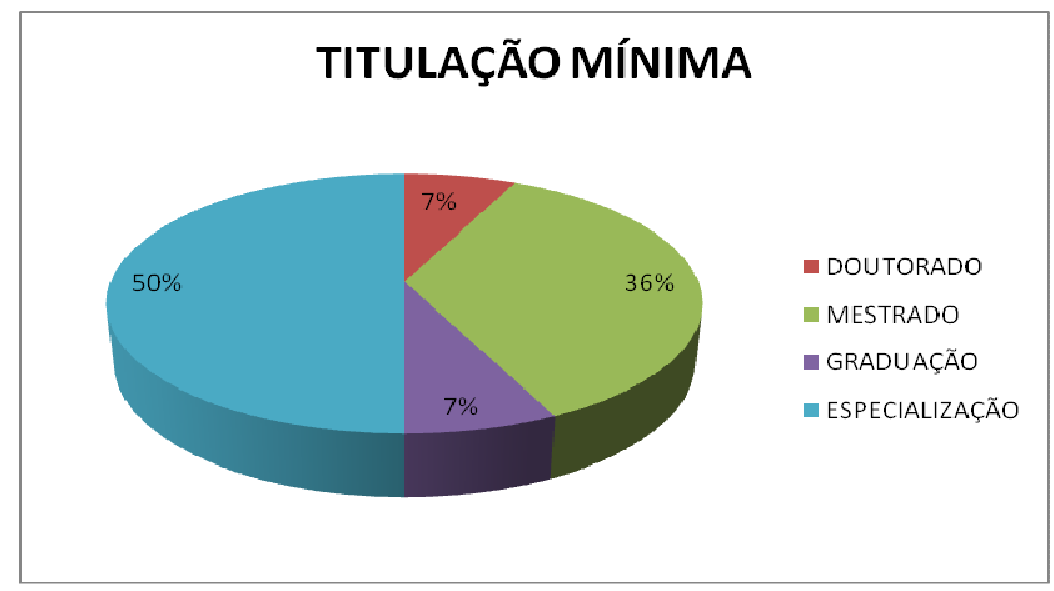

Gráfico 1: Titulação mínima dos professores participantes.

Vale destacar que grande parte dos professores que possuem uma baixa titulação são representantes de Instituições de Ensino Superior das regiões Norte e Nordeste do país. Entendemos como baixa titulação aquela que seja inferior a de Mestre, principalmente por estarmos lidando nesse momento com IES públicas. Nas regiões Sul e Sudeste, a maioria das IES públicas exigem para seus docentes a titulação mínima de Doutor. Portanto, esses dados são preocupantes e nos alertam para a necessidade de promover a continuidade de formação dos professores graduados e especialistas (que juntos representam 57\% do total) a fim de qualificar o corpo docente das referidas instituições.

De acordo com o Gráfico 2, podemos verificar que dois professores (cerca de 14\%) não foram atletas de handebol e que a grande maioria dos professores, 12 deles exatamente (representantes de $86 \%$ do total de participantes), já foram atletas desta modalidade esportiva antes de se tornarem docentes. Isso ratifica o forte vínculo estabelecido pelos

\footnotetext{
${ }^{5}$ Contando com um dos autores desse artigo, estavam participando do Encontro somente quatro professores com a titulação de Doutor.
}

Conexões: revista da Faculdade de Educação Física da UNICAMP, Campinas, v. 10, n. 2, p. 103-120, maio/ago. 2012.108 ISSN: 1983-9030 
docentes com essa modalidade esportiva o que pode contribuir positivamente para a qualidade do curso. Entretanto, a simples experiência como atleta torna-se insuficiente para garantir o oferecimento de um bom curso se não for atrelada à especialização, estudos, contato com literatura e pesquisas atualizadas, enfim, esta prática deve ser respaldada pela formação continuada do docente.

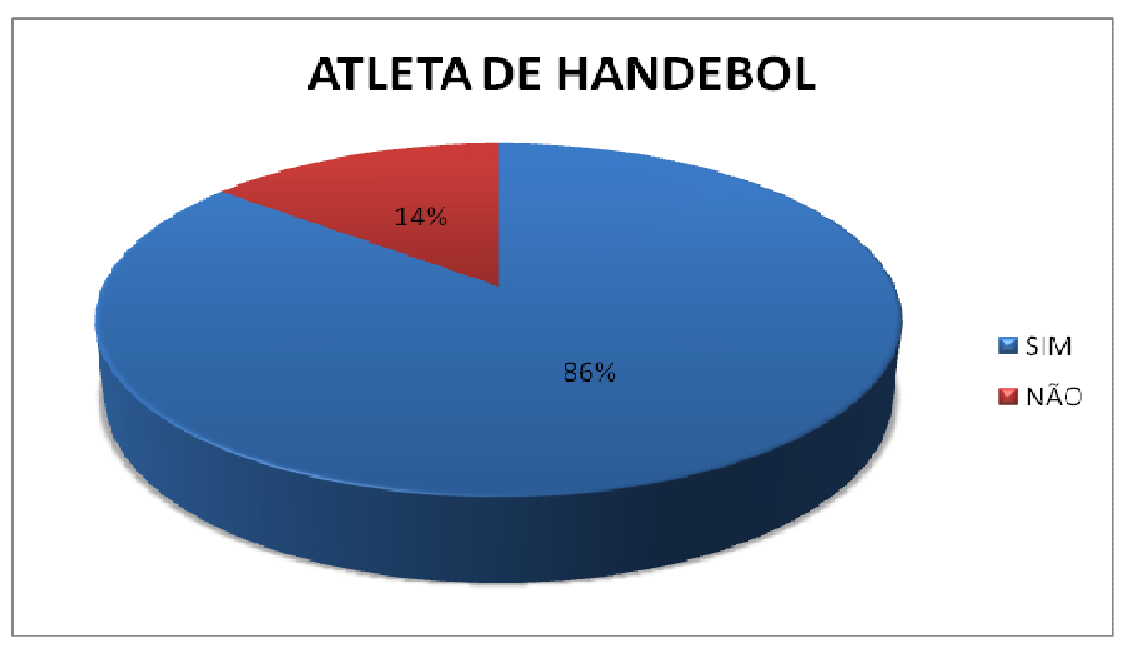

Gráfico 2: Porcentagem de professores que já foram atletas de handebol.

Para finalizar esta primeira etapa de análise explicitaremos, conforme Gráfico 3, a modalidade de curso em que os professores participantes lecionam. A grande maioria dos docentes (cerca de $86 \%$ do total) leciona para a modalidade de curso licenciatura, um professor leciona no bacharelado enquanto que um único professor leciona em ambas.

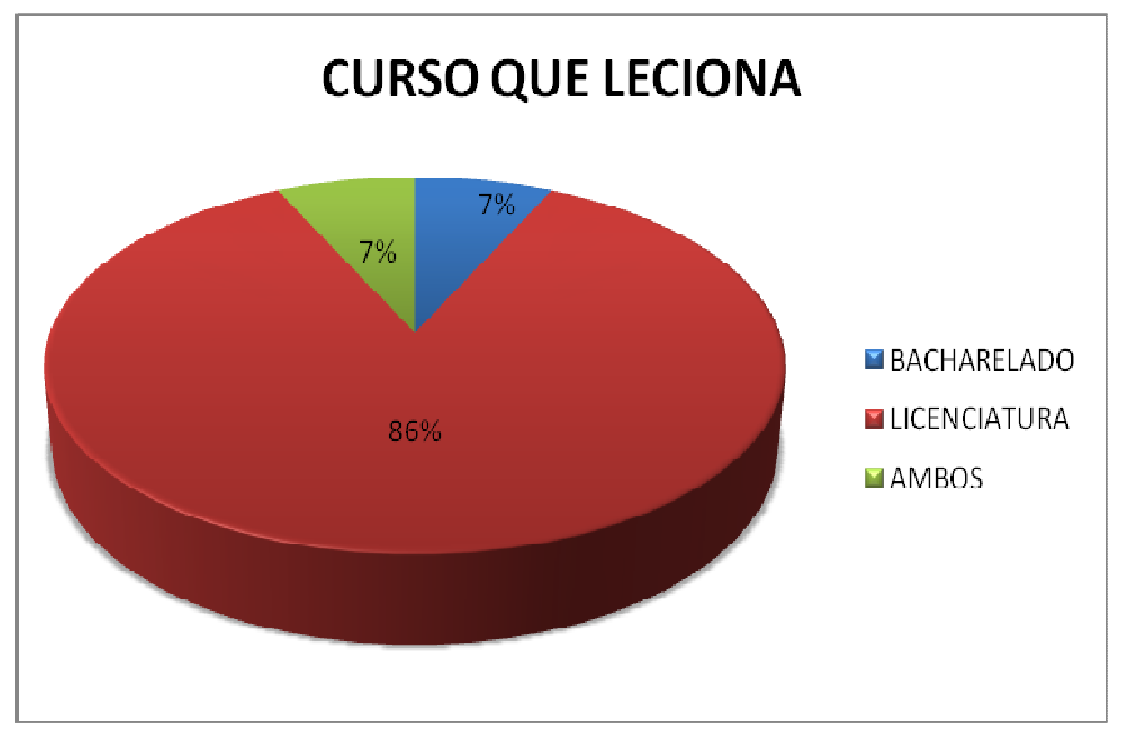

Conexões: revista da Faculdade de Educação Física da UNICAMP, Campinas, v. 10, n. 2, p. 103-120, maio/ago. 2012.109 ISSN: 1983-9030 
Gráfico 3: Modalidade de curso em que lecionam.

Ao iniciarmos agora nossa segunda etapa de análise dos dados, focaremos as características das IES públicas representadas pelos docentes participantes deste estudo a partir dos seguintes aspectos: a quantidade de disciplinas que cada professor oferece, o número de alunos matriculados por turma, as condições das instalações e a qualidade do material didático utilizado.

Como vimos anteriormente, grande parte dos docentes leciona na modalidade de curso licenciatura. Ainda assim, o máximo de disciplinas obrigatórias que cada docente ministra é duas. Ou seja, 9 professores (cerca de 64\%) lecionam uma única disciplina, três docentes (cerca de 22\%) ministram duas disciplinas e há ainda um docente que ministra somente uma disciplina, mas não obrigatória (eletiva/optativa).

Por sua vez, esses dados tornam-se pouco relevantes se não considerarmos a carga horária total destinada por cada professor para o curso de handebol (seja em uma ou duas disciplinas obrigatórias). O número de disciplinas obrigatórias ministradas por professor e a carga horária total destinada para o curso de handebol estão representadas na Tabela 1.

Tabela 1 - Quantidade e porcentagem de carga horária total destinada aos cursos de Handebol que oferecem uma, duas ou mais de duas disciplinas.

\begin{tabular}{|c|c|c|}
\hline Disciplinas/Horas & & POR \\
\hline UMA DISCIPLINA OBRIGATÓRIA & QUAN & $\mathbf{6 4 \%}$ \\
\hline HORAS DEDICADAS AQUELES QUE LECIONAM UMA DISCIPLINA & & $4 \%$ \\
\hline 54 & 1 & $26 \%$ \\
\hline 60 & 3 & $4 \%$ \\
\hline 72 & 1 & $4 \%$ \\
\hline HORAS DEDICADAS AQUELES QUE LECIONAM DUAS DISCIPLINAS & 1 & $\mathbf{2 2 \%}$ \\
\hline 90 & $\mathbf{3}$ & $8 \%$ \\
\hline DUAS DISCIPLINAS OBRIGATÓRIAS & 1 & $8 \%$ \\
\hline MAIS DE DUAS DISCIPLINAS OBRIGATÓRIAS & 1 & $\mathbf{0}$ \\
\hline Omissões & $\mathbf{1}$ & $\mathbf{7 \%}$ \\
\hline
\end{tabular}


A partir da Tabela 1 podemos constatar que os nove professores que ministram uma única disciplina destinam ao curso, de 54 a 136 horas sendo que a grande parcela (6 professores) destina de 60 a 68 horas para o cumprimento do curso de handebol. Por sua vez, dentre os professores que ministram duas disciplinas ( 3 professores) a carga horária total varia de 80 a 160 horas.

Consideramos que para o cumprimento de um programa de handebol que dê conta de atender com qualidade aos conteúdos deste tema são necessárias, no mínimo, 60 horas/aula. Dessa forma, a partir dos dados levantados por esta pesquisa, constatamos que, independente se os conteúdos desta modalidade foram fracionados em uma ou duas disciplinas obrigatórias, a grande maioria das IES analisadas, ou seja, 96\% delas, destinam durante o curso de handebol uma carga horária mínima de 60 horas, chegando em alguns casos, duas IES especificamente (16\%), ao dobro da carga horária defendida por nós como mínima para o ensino de handebol voltado à formação de professores e profissionais de educação física no ensino superior de modo competente.

A diferença de horas que são dedicadas para o cumprimento dos conteúdos de um curso de handebol retrata a falta de sintonia entre as IES ou ausência de um padrão no estabelecimento da carga horária precisa para o oferecimento de um curso desta natureza.

Dentre os aspectos mais significativos para o oferecimento de um curso de qualidade, certamente um deles passa pelo número de alunos presentes em cada turma. Nesse ponto, nas IES analisadas neste estudo, conforme as Tabelas 2 e 3, as turmas apresentam um número mínimo de alunos matriculados que varia de 15 a 70 alunos e um número máximo que oscila entre 28 e 80 discentes. No entanto, a grande maioria (cerca de $71 \%$ ) possui no mínimo de 15 a 25 alunos matriculados, outros $21 \%$ possuem entre 30 e 50 e uma única IES possui no mínimo 70 alunos por turma. Já em relação ao número máximo de alunos matriculados, verificamos que a maior parcela das IES contam em suas turmas com um número máximo de alunos que varia de 28 a 38 matriculados, outros $28 \%$ possuem de 40 a 50 e uma outra conta com até 80 alunos em sala de aula por turma. 
Tabela 2 - Quantidade e percentual aproximado do número mínimo de alunos por turma.

\begin{tabular}{ccc}
\hline \multicolumn{3}{c}{ MIN } \\
& QUAN & POR \\
\hline 15 a 25 & 10 & $71 \%$ \\
30 a 50 & 3 & $21 \%$ \\
70 & 1 & $7 \%$ \\
\hline
\end{tabular}

Tabela 3 - Quantidade e percentual aproximado do número máximo de alunos por turma.

\begin{tabular}{ccc}
\hline & MAX \\
& QUAN & POR \\
\hline 28 a 38 & 9 & $64 \%$ \\
40 a 50 & 4 & $29 \%$ \\
51 a 80 & 1 & $7 \%$ \\
\hline
\end{tabular}

Entendemos que o número necessário de alunos matriculados para o oferecimento de um curso de qualidade, contando com somente um professor e, portanto, sem auxiliares, deva ser em média de 30 alunos por turma. As boas experiências em cursos de graduação ${ }^{6}$ comprovam a necessidade de o professor acompanhar e estar atento à execução dos movimentos de cada aluno, corrigindo e ensinando o modo apropriado para tal fim, além de estimular e desenvolver observações críticas e debates em torno das situações problemas de jogo, assim como as possíveis escolhas táticas dos seus alunos/jogadores. ${ }^{7}$ Isso ratifica a importância deste número não extrapolar a média de 30 alunos por turma, visto que prejudicaria sobremaneira a atenção destinada pelo professor a cada aluno. Portanto, turmas com mais de 38 alunos (caso de 36\% das IES analisadas) são inapropriadas para o bom andamento do curso. Tal fato demonstra uma tendência ao sucateamento do ensino público, já evidenciadas nas escolas públicas paulistas desde a década de 1990 quando passaram a ser constituídas turmas de educação física que contavam com até 50 alunos. ${ }^{8}$

Outro ponto importante para a qualidade de um curso refere-se às instalações disponíveis aos docentes e discentes. Dessa forma, quando questionados acerca das condições das instalações nas IES as quais eles lecionam, os professores participantes desta pesquisa responderam, em sua grande maioria (cerca de $71 \%$ ) que as condições são adequadas.

\footnotetext{
${ }^{6}$ Sobre o tema consultar: PIROLO, Alda L. A disciplina voleibol nos cursos de licenciatura em Educação Física do Paraná: processo de conhecimento crítico-reflexivo? In: COSTA, Vera L. (Org.). Formação Profissional Universitária em Educação Física. Rio de Janeiro: Ed. Central da Gama Filho, $1997 ;{ }^{5}$ TERRA, Dinah V. Ensino crítico-participativo das disciplinas técnico-desportivas nos cursos de licenciatura em Educação Física: análise do impacto de um projeto de ensino no handebol. In: COSTA, Vera L. (Org.). Formação profissional universitária em Educação Física. Rio de Janeiro: Ed. Central da Gama Filho, 1997. ${ }^{6}$

${ }^{7}$ Queremos com isso dizer que no curso superior de educação física os alunos são ao mesmo tempo os executores (aprendizes) e os avaliadores dos diversos meios técnico-táticos das modalidades esportivas, assim como de todos os outros elementos do jogo coletivo.

${ }^{8}$ Em IES particulares, assim como retratado por REIS e CASTELLANI (no prelo), é comum a existência de turmas com que contam com 60, 70 ou até mais alunos matriculados.

Conexões: revista da Faculdade de Educação Física da UNICAMP, Campinas, v. 10, n. 2, p. 103-120, maio/ago. 2012.112 ISSN: 1983-9030
} 
Ainda três professores (correspondentes a $21 \%$ do total) afirmaram ser muito adequada e um único professor $(7 \%)$, pouco adequada.

Entendemos como instalações adequadas para o oferecimento de um curso de handebol de qualidade uma quadra (preferencialmente coberta e iluminada, se necessário) que possua as dimensões oficiais da modalidade, ou seja, 40 metros de cumprimento por 20 metros de largura, salas de aula equipadas com vídeo, internet e data show e uma biblioteca com literaturas diversificadas no campo do handebol e áreas correlatas.

Quando questionados acerca das condições/qualidade do material didático disponibilizados pela IES para o oferecimento do curso de handebol, a maior parcela dos professores (cerca de $64 \%$ ) afirmou que o material oferecido é adequado, $22 \%$ como muito adequado e somente dois docentes (representando $14 \%$ do total) entendem que os materiais disponibilizados são pouco adequados. Consideramos que as condições e qualidade do material didático são adequadas ou muito adequadas se forem oferecidas aos docentes bolas de handebol para as diversas categorias $(\mathrm{H} 1, \mathrm{H} 2 \text { e H3 })^{9}$, bolas de iniciação esportiva, materiais de apoio diversificados, ou seja, cones, cordas, etc, além de uma quantidade significativa de exemplares dos livros adotados pelo professor como base e/ou referência no seu curso.

As condições das instalações e a qualidade do material didático oferecidas pelas IES representadas pelos professores participantes deste estudo estão representadas respectivamente nos Gráficos 6 e 7.

\footnotetext{
${ }^{9}$ O handebol tem três tamanhos de bola que vão desde H1 a H3 e provavelmente a falta de condições melhores declaradas pelos 10 professores que representam $23 \%$ do total deve-se ao fato de nem sempre ser observado na compra dos materiais essa diversidade, fazendo com que os professores utilizem bolas de tamanhos e pesos inadequados a categoria que está ensinando, ou seja, para homens adultos deveria ser utilizada a bola $\mathrm{H} 3$ e para as mulheres adultas bolas $\mathrm{H} 2$.
}

Conexões: revista da Faculdade de Educação Física da UNICAMP, Campinas, v. 10, n. 2, p. 103-120, maio/ago. 2012. 113 ISSN: 1983-9030 


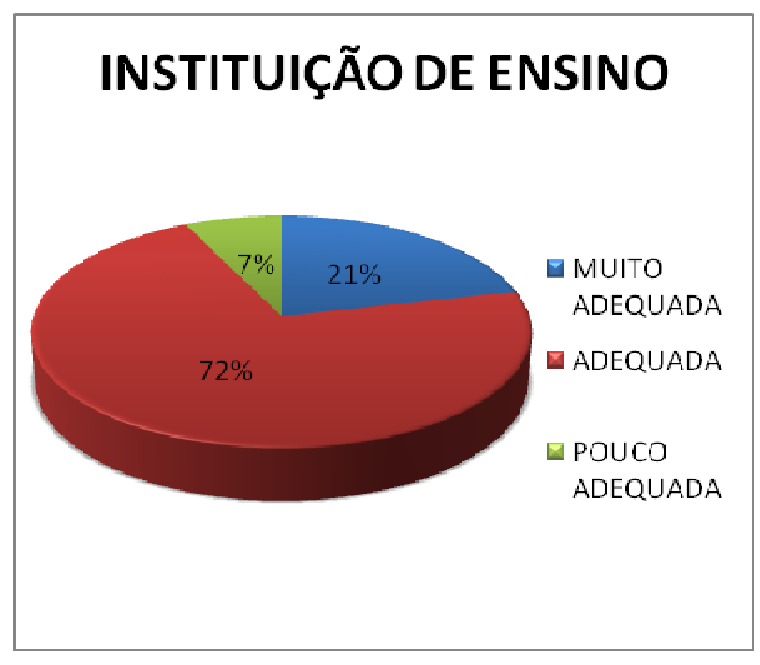

Gráfico 6: Condições das instalações das IES.

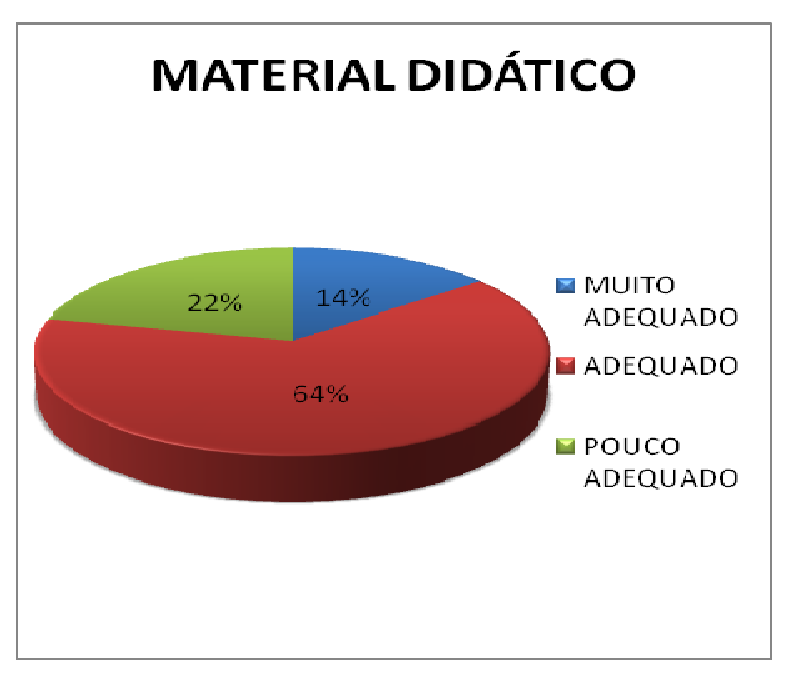

Gráfico 7: Qualidade do material didático utilizado.

Para finalizar nossas análises voltamos nosso foco às informações que, apesar de ainda importantes e fundamentais para a qualidade do curso oferecido, possuem pouca responsabilidade das Instituições de Ensino Superior visto que são os docentes quem optam pelos conteúdos a serem desenvolvidos no decorrer do curso e pelo método de ensino-aprendizagem a ser utilizado. Ambos aspectos são tidos por nós como extremamente significativos para a qualidade do curso, pois apontam um caminho pedagógico que provavelmente será adotado pelos alunos quando futuramente estiverem em atividades profissionais e retratam o grau de conhecimento dos docentes acerca da disciplina ministrada, nos esclarecendo o perfil do curso de handebol que é oferecido por tais professores.

Dentre os conteúdos citados pelos professores, conforme o gráfico 8 , podemos constatar que os únicos conteúdos presentes no curso de todos os professores são os sistemas defensivos e os meios táticos ofensivos e defensivos. Logo em seguida foram citados por 93\% dos professores os fundamentos, os sistemas ofensivos e o mini-handebol. 12 Professores, correspondentes a $86 \%$ do total de participantes, elencaram também os conteúdos: histórico, regras e postos específicos de goleiros. O conteúdo postos específicos de pivôs/pontas/armadores foi citado por $79 \%$ dos docentes e somente cinco professores 
(cerca de $36 \%$ ) mencionaram a periodização. Com exceção do handebol de praia ${ }^{10}$, todos os conteúdos mencionados são necessários e considerados como mínimos num curso superior de handebol.

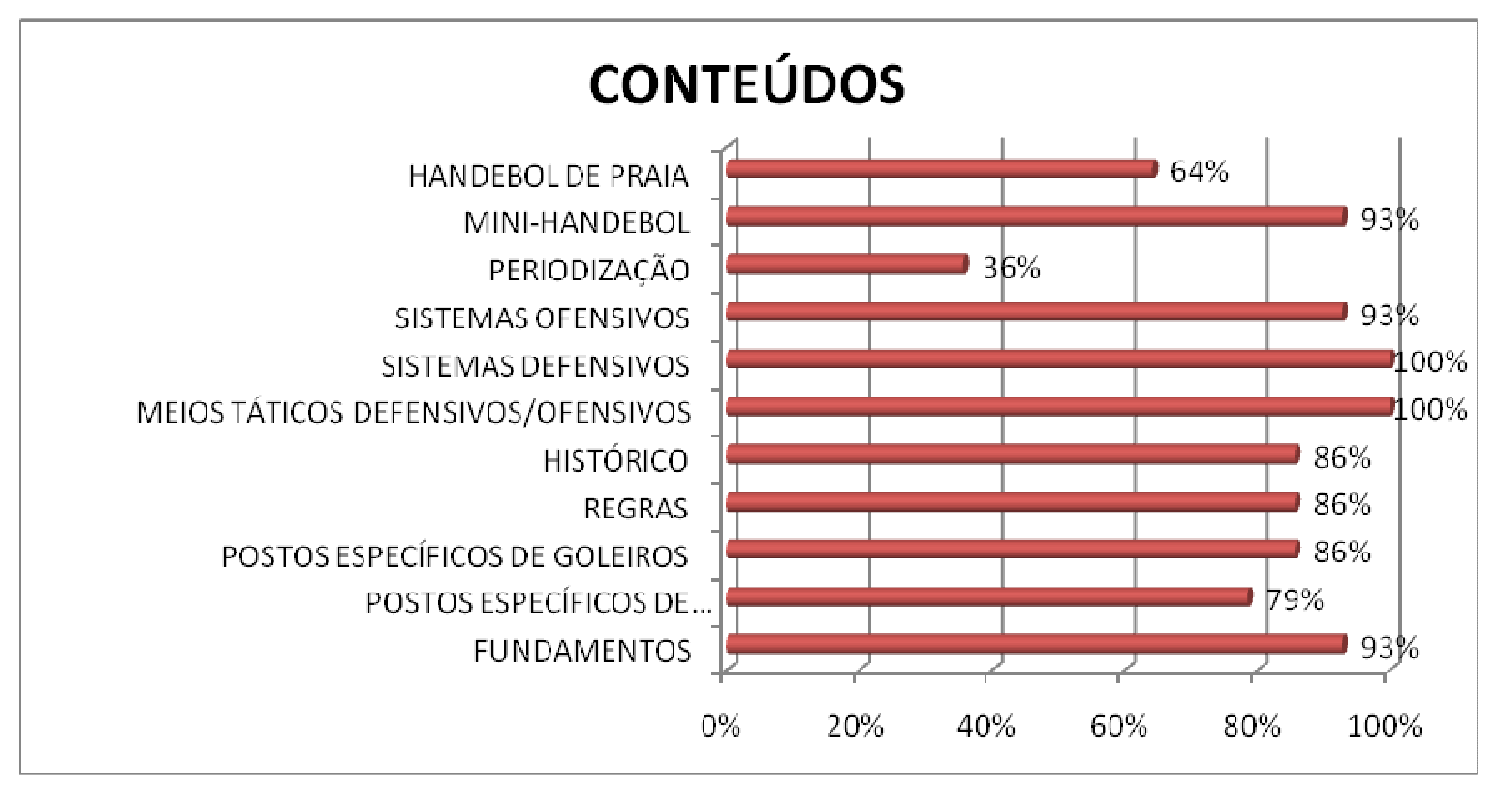

Gráfico 8: Conteúdos que fazem parte dos cursos de handebol.

Dentre os conteúdos citados, os fundamentos mereceram de nós uma análise mais profunda. Entendemos como fundamento a denominação histórica designada aos gestos técnicos em uma modalidade esportiva, por qualquer que seja. No entanto, com a criação de uma nova área de estudo, a pedagogia do esporte, tal denominação começa a perder força a partir do início do século XXI, visto que as produções realizadas por esta nova área trouxeram em substituição aos fundamentos a denominação meios técnico-táticos. $\mathrm{O}$ argumento levantado pela pedagogia do esporte para substituir a denominação de fundamentos em meios técnico-táticos se sustenta, sobretudo, pela característica coletiva da modalidade, na necessidade de se partir do pressuposto de que é preciso decidir pela ação a ser adotada em determinadas situações manifestadas nos jogos, ou seja, resolver um problema apresentado e imprevisível, tendo para esta finalidade a utilização dos meios técnicos para solucionar uma questão tática. Dessa forma, o como se faz um determinado

10 Apesar da $\mathrm{CBHb}$ apelar em seus encontros anuais para que os professores de handebol tratem esse conteúdo em seus cursos, a consideramos uma outra modalidade esportiva.

Conexões: revista da Faculdade de Educação Física da UNICAMP, Campinas, v. 10, n. 2, p. 103-120, maio/ago. 2012.115 ISSN: 1983-9030 
gesto esportivo passou a ser subjetivo, pois sem saber o que resolver diante de uma situação de jogo, a exatidão do gesto parece desnecessária . ${ }^{7}$

Os fundamentos citados pelos professores participantes desta pesquisa, conforme retratado no Gráfico 9, são: passe, arremesso, recepção, drible e empunhadura. Dentre eles, o mais citado foi o passe (cerca de 62\%), seguido de perto pelo arremesso e recepção (ambas presentes em 54\% das respostas). Ainda como fundamentos trabalhados, o drible e a empunhadura foram citados, respectivamente, por $46 \%$ e $15 \%$ dos professores. Tiveram ainda docentes que não especificaram os fundamentos trabalhados (23\%) e outros (15\%) que afirmaram trabalhar com todos, não especificando quais. No entanto, dois dados nos preocupam: um deles refere-se à ausência dos fundamentos ritmo trifásico e duplo ritmo trifásico ${ }^{11}$ nas respostas; Outro também preocupante, no nosso entendimento, refere-se às denominações dadas pelos professores aos fundamentos, apontando como fundamentos alguns meios táticos ofensivos/defensivos e sistemas ofensivos/defensivos assim como a finta, progressão, deslocamento, "posicionamento de defesa", entre outros. A finta, por exemplo, apesar de ser citada por $31 \%$ dos professores, não é considerada pela literatura um fundamento, pois é entendida como um meio tático ofensivo, semelhante ao acontecido com a progressão, citada por $23 \%$ dos professores.

Apesar de citados em pequena proporção, o bloqueio, posicionamento defensivo e ofensivo, a marcação, manejo de bola e os deslocamentos também foram citados pelos professores como fundamentos trabalhados. Se considerarmos que não há na literatura sobre handebol tais denominações como sendo fundamentos, este índice requer uma análise mais atenta. Isso se justifica na medida em que se espera que uma grande parcela, preferencialmente todo o corpo docente, compreenda a diferenciação entre fundamentos, meios táticos ofensivos e defensivos e sistemas ofensivos e defensivos. Mais recentemente, todos os fundamentos, tais como: a empunhadura, o passe, a recepção, o drible, o arremesso, o ritmo trifásico e o duplo ritmo trifásico (esses últimos não apareceram nas respostas) são denominados de elementos ou meios técnico-táticos. Não obstante, estas

\footnotetext{
${ }^{11}$ Conhecidos na linguagem de quadra como 3 passadas e 7 passos. Nem mesmo assim, foram mencionados pelos professores.
}

Conexões: revista da Faculdade de Educação Física da UNICAMP, Campinas, v. 10, n. 2, p. 103-120, maio/ago. 2012.116 ISSN: 1983-9030 
denominações e compreensão acerca dos fundamentos do handebol são transmitidas pelos professores dos cursos das IES aos alunos de graduação em Educação Física que irão reproduzir, quando formados, seu aprendizado para milhares de crianças e jovens, por meio da sua prática pedagógica, fato que nos preocupa demasiadamente.

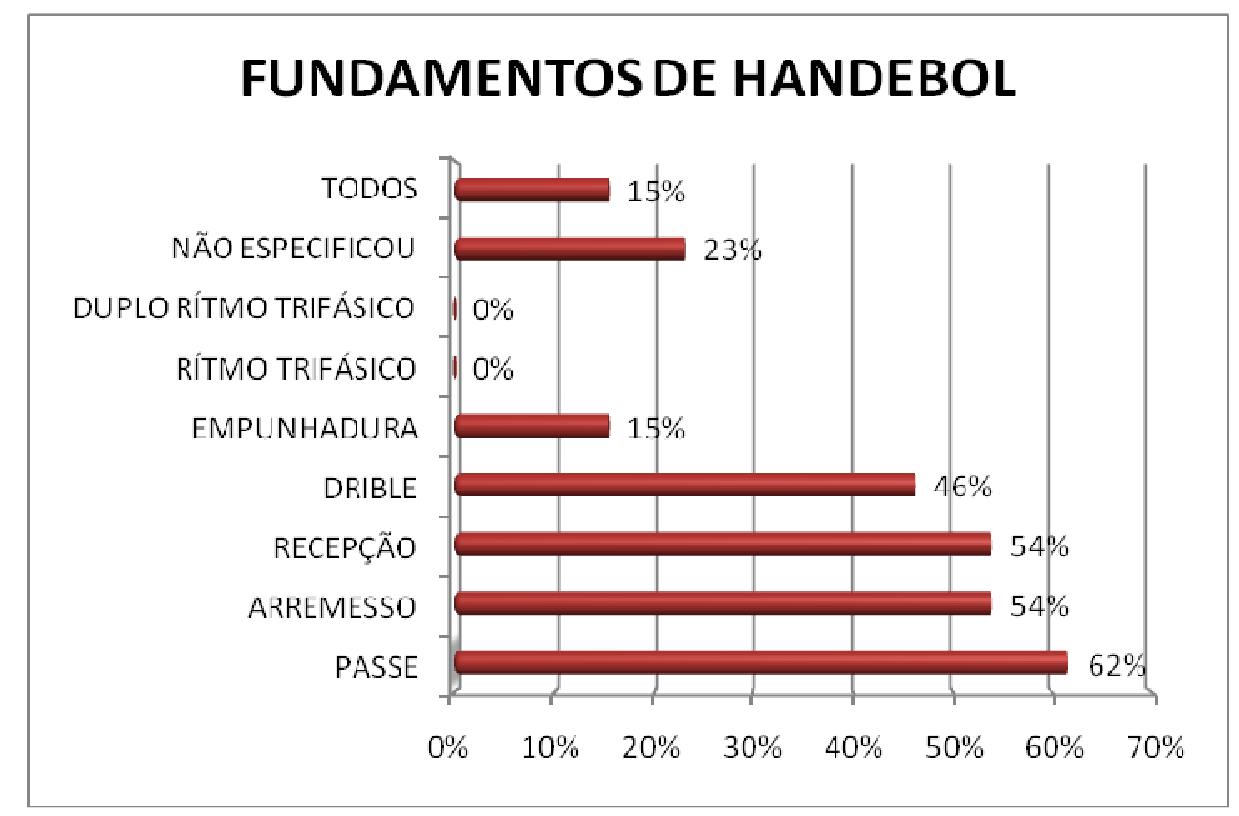

Gráfico 9: Fundamentos trabalhados pelos professores nos cursos de handebol.

Para finalizar as nossas análises iremos nos deter aos métodos de ensino utilizados pelos professores durante o curso de handebol ministrado por eles nas IES que lecionam. De acordo com o gráfico 10, abaixo representado, o método misto de ensino e aprendizagem é o mais utilizado (cerca de 64\%) pelos professores. Em seguida, presente nos cursos de $36 \%$ dos docentes, está o método Iniciação Esportiva Universal (IEU), proposto por Greco \& Benda (1998). Apenas um professor (correspondente a 7\% das citações) afirmou trabalhar no curso a partir do método de ensino global e nenhum professor manifestou trabalhar com o método parcial. Quatro professores, ou seja, cerca de $28 \%$ do total de participantes da pesquisa, afirmou trabalhar ainda com outros métodos de ensino, tais quais: "Aprendizagem significativa de Sunsuel", "Conceito recreativo de jogos esportivos" e "Grandes e pequenos jogos".

Apesar da maior incidência percentual dos métodos Misto e IEU nos cursos de handebol 
oferecidos nas IES públicas brasileiras analisadas, salientamos que todos possuem vantagens e desvantagens, cabendo ao professor adotar por um método que melhor se adéquie aos seus objetivos, necessidades e às características bio-psico-social do grupo que se propõe trabalhar, discurso defendido por Reis (2006) e também utilizado por um dos professores participantes deste estudo.

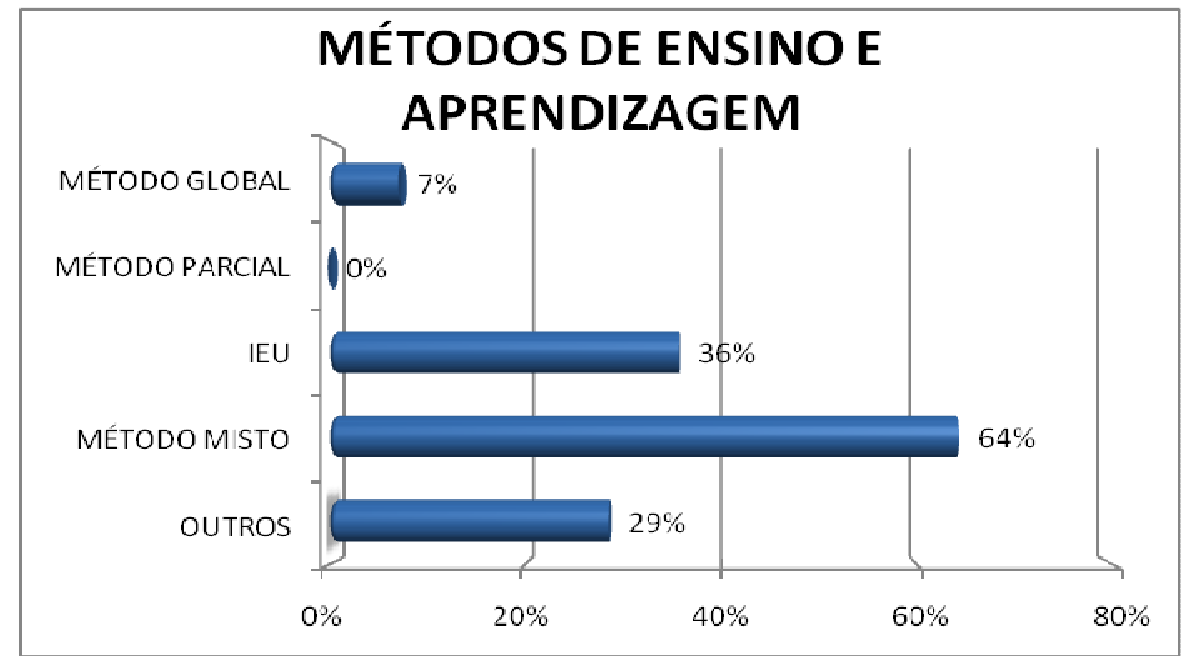

Gráfico 10: Métodos de ensino e aprendizagem adotados pelos professores nos cursos de handebol.

\section{CONSIDERAÇÕES FINAIS}

O ensino superior público e de qualidade para a população só pode ser garantido na medida em que o corpo docente e as condições e estrutura de trabalho oferecidas pelas IES a estes docentes e aos alunos forem adequadas. Portanto, nosso foco nestes dois aspectos se justifica por compreendermos que juntos podem garantir, ou não, o oferecimento de um bom curso de handebol para alunos de graduação em Educação Física.

No entanto, vimos que a esperada titulação mínima de mestre para os docentes de IES públicas, não foi confirmada já que dentre os 14 participantes $57 \%$ deles são especialistas ou graduados. Por sua vez, o fato de $86 \%$ destes professores já terem sido handebolistas denota a forte relação que possuem com a modalidade, e suas experiências obtidas como atleta devem contribuir tanto para o conhecimento acumulado sobre o tema, quanto para o gosto e prazer em transmitir esse conhecimento aos alunos. Apesar de valorizarmos a experiência obtida como atletas, acreditamos que o corpo docente, no Brasil como um 
todo, deve ser qualificado tendo em sua maioria doutores, como já se verifica nas IES públicas do sul e sudeste do país.

Sugere-se novas pesquisas sobre o tema tendo como opção metodológica a observação de aulas nas IES públicas para que se tenha conhecimento da realidade do ensino do handebol nos cursos de formação em Educação Física. Neste aspecto, Souza ${ }^{1: 226}$ pode constatar nas aulas que observou que os professores "ainda apresentam o modelo de aula centrado e desenvolvido na aplicação dos conteúdos da aptidão física”. Tal fato retrata a dificuldade dos docentes em transpor para a prática os conhecimentos sobre as diferentes teorias que sustentam estar perspectiva. "Ou seja, não conseguem transformar suas ações que são meramente práticas, em práxis dialética pedagógica."

Não obstante, ressaltamos a importância da continuidade do Encontro Nacional de professores de Handebol das Instituições de Ensino Superior, promovido pela $\mathrm{CBHb}$, a fim de qualificar esse processo de atualização teórica e formação continuada dos docentes com a consequente melhora no perfil dos cursos de handebol da IES brasileiras. Souza ${ }^{1}$ reforça em suas conclusões a nossa ressalva visto que notou em sua pesquisa que "há falta de conhecimento específico sobre metodologias e procedimentos pedagógicos."

\section{REFERÊNCIAS}

\section{${ }^{1}$ SOUZA, N. P. O ensino das disciplinas esportivas coletivas nos cursos de licenciatura} em Goiás: um estudo descritivo. 2007. Tese (Doutorado em Educação Física) - Faculdade Educação Física, Universidade Estadual de Campinas, Campinas, 2007.

${ }^{2}$ CASTELLANI FILHO, L. Formação em Educação Física no âmbito da educação superior brasileira: aproximações ao cenário sulamericano. In: CATANI, A. M. (Org.). Políticas de educação superior na América Latina: mais impasses do que possibilidades? São Paulo: Mercado de Letras, 2012.

\footnotetext{
${ }^{3}$ TERRA, D. V. O ensino crítico-participativo no contexto das disciplinas técnicodesportivas nos cursos de licenciatura em educação física: análise do impacto de um 
projeto de ensino no handebol. 1996. Dissertação (Mestrado em Educação Física) Universidade Gama Filho, Rio de Janeiro, 1996.

${ }^{4}$ RODRIGUES, A. T. A questão da formação de professores de educação física e a concepção de professor enquanto intelectual - reflexivo - transformador. Pensar a Prática, Goiânia, v. 1, p. 38-47, 1998.

${ }^{5}$ PIROLO, A. L. A disciplina voleibol nos cursos de licenciatura em Educação Física do Paraná: processo de conhecimento crítico-reflexivo? In: COSTA, V. L. (Org.). Formação profissional universitária em Educação Física. Rio de Janeiro: Ed. Central da Gama Filho, 1997.

${ }^{6}$ TERRA, D. V. Ensino crítico-participativo das disciplinas técnico-desportivas nos cursos de licenciatura em Educação Física: análise do impacto de um projeto de ensino no handebol. In: COSTA, V. L. (Org.). Formação profissional universitária em Educação Física. Rio de Janeiro: Ed. Central da Gama Filho, 1997.

${ }^{7}$ GARGANTA, J. Para uma teoria dos jogos desportivos colectivos. In: GRAÇA A.; OLIVEIRA, J. (Ed.). O Ensino dos jogos desportivos. 2. ed. Porto: Faculdade de Ciências do Desporto e de Educação Física. Porto: Centro de Estudos dos Jogos Desportivos, 1995. p. 11-25.

Recebido em: 29 outubro 2011. Aceito em: 11 julho 2012. 